CZASOPISMO INŻYNIERII LA¿OWEJ, ŚRODOWISKA I ARCHITEKTURY JOURNAL OF CIVIL ENGINEERING, ENVIRONMENT AND ARCHITECTURE

JCEEA, t. XXXIII, z. 63 (1/I/16), styczeń-marzec 2016, s. 149-156

\author{
Kostiantyn PROTCHENKO ${ }^{1}$ \\ Joanna DOBOSZ ${ }^{2}$ \\ Marek URBAŃSKI ${ }^{3}$ \\ Andrzej GARBACZ ${ }^{4}$
}

\title{
WPEYW SUBSTYTUCJI WŁÓKIEN BAZALTOWYCH PRZEZ WŁÓKNA WĘGLOWE NA WŁAŚCIWOŚCI MECHANICZNE PRĘTÓW B/CFRP (HFRP)
}

\begin{abstract}
W niniejszym artykule przedstawiono analityczne i numeryczne obliczenia mechanicznych właściwości obecnie opracowywanych prętów hybrydowych HFRP (Hybrid Fibre Reinforced Polymer) powstałych poprzez zastąpienie (substytucję) części włókien bazaltowych BFRP (Basalt Fibre Reinforced Polymer) włóknami węglowymi CFRP (Carbon Fibre Reinforced Polymer). W tym aspekcie termin „substytucja” rozumiany będzie jako modyfikacja prętów BFRP polegająca na zastąpieniu pewnej części włókien bazaltowych przez włókna węglowe.

Celem analizy jest określenie optymalnego modelu prętów hybrydowych HFRP, które stanowiłyby realną alternatywę dla prętów stalowych stosowanych do zbrojenia konstrukcji betonowych. Zamiana włókien bazaltowych, włóknami węglowymi prowadzi do uzyskania lepszych właściwości mechanicznych prętów. Względy ekonomiczne skłaniają do ograniczenia procentowego udziału włókien węglowych w prętach HFRP do rozsądnej wielkości, oraz zastosowaniu włókien węglowych o stosunkowo niedużej wytrzymałości (Low Strength Carbon Fibres) jak na włókna CFRP. $\mathrm{W}$ pracy przedstawiony został opis struktury pręta hybrydowego, oszacowanie właściwości mechanicznych wzdłuż i w poprzek włókien, a także wpływ układu włókien w przekroju poprzecznym pręta na jego zachowanie mechaniczne.

Analizę przeprowadzono dla różnych proporcji udziału włókien węglowych do włókien bazaltowych $(1: 9 ; 1: 4 ; 1: 3 ; 1: 2 ; 1: 1)$ w prętach HFRP. Rozpatrzono dwa przypadki rozmieszczenia włókien w przekroju poprzecznym pręta (Bar Architecture). Pierwszy $\mathrm{z}$ włóknami węglowymi zlokalizowanymi w rdzeniu, natomiast drugi z włóknami węglowymi usytuowanymi w powierzchniowej warstwie pręta.
\end{abstract}

Słowa kluczowe: Hybrydowy pręt C/BFRP, HFRP, BFRP, CFRP, układ włókien

\footnotetext{
${ }^{1}$ Autor do korespondencji/corresponding author: Kostiantyn Protchenko, Politechnika Warszawska, ul. Armii Ludowej 16, 00636, Warszawa, 22 8255758, k.protchenko@il.pw.edu.pl

2 Joanna Dobosz, Politechnika Warszawska, ul. Armii Ludowej 16, 00636, Warszawa, j.dobosz@il.pw.edu.pl

${ }^{3}$ Marek Urbański, Politechnika Warszawska, ul. Armii Ludowej 16, 00636, Warszawa, m.urbanski@il.pw.edu.pl

4 Andrzej Garbacz, Politechnika Warszawska, ul. Armii Ludowej 16, 00636, Warszawa, 22 2346556, a.garbacz@il.pw.edu.pl
} 


\section{Wstęp}

Jednym z mechanizmów niszczenia żelbetu jest korozja stalowych prętów, między innymi z powodu karbonatyzacji otuliny betonowej. Aby uniknąć niekorzystnych skutków spowodowanych tym zjawiskiem, zamiast typowych rozwiązań w postaci zabezpieczeń antykorozyjnych, można zastosować materiały o zwiększonej odporności na korozję.

W pewnych okolicznościach, użycie prętów kompozytowych FRP (Fibre Reinforced Polymer) może być traktowane jako alternatywne rozwiązanie w stosunku do konwencjonalnego zbrojenia stalowego. W porównaniu do zbrojenia stalowego, zastosowanie wewnętrznego zbrojenia FRP w konstrukcjach betonowych, może przyczynić się do zwiększenia ich nośności i trwałości [7]. Materiały kompozytowe stworzone na bazie FRP, ze względu na znacznie dłuższą żywotność, stanowią obiecujący zamiennik stali zbrojeniowej [10].

Koszt produkcji prętów CFRP (Carbon Fibre Reinforced Polymer) jest stosunkowo wysoki. Optymalnym rozwiązaniem uwzględniającym relację kosztów do właściwości mechanicznych jest zastosowanie prętów HFRP (Hybrid Fibre Reinforced Polymer) na bazie włókien bazaltowych, z substytucją włóknami węglowymi. Pręty HC/BFRP (Hybrid Carbon/Basalt Fibre Reinforced Polymer) charakteryzują się lepszymi właściwościami mechanicznymi niż pręty BFRP (Basalt Fibre Reinforced Polymer) przy relatywnie niskim koszcie, w porównaniu z prętami CFRP [5]. Ponadto koszt prętów HC/BFRP może być konkurencyjny w stosunku do kosztu prętów stalowych o porównywalnych właściwościach.

Niektóre sugestie odnoszące się do hybrydyzacji materiałów na bazie FRP można znaleźć w pracach naukowych w [2], [11], [12].

\section{Charakterystyka pręta}

\subsection{Opis struktury pręta}

Pręt hybrydowy stworzony na bazie FRP składa się z więcej niż jednego rodzaju włókien połączonych jednym lub kilkoma rodzajami matrycy.

Strukturę pręta może stanowić jedna, dwie lub więcej żyłek skręconych spiralnie wokół podłużnej osi pręta. Pojedyncza żyłka składa się z dużej ilości włókien zatopionych w matrycy. Włókna na całej swojej długości są ciągłe, ukierunkowane i nie przecinają się pomiędzy sobą. Strefa kontaktu pomiędzy żyłkami składa się z matrycy i z mniejszej niż w żyłce ilości włókien.

$\mathrm{W}$ niniejszej pracy analizowano pręty o matrycy z żywicy epoksydowej wzmocnionej włóknami bazaltowymi i węglowymi, które stanowią 80-procent całkowitej objętości pręta. Na Rys. 1 przedstawiono dwa rodzaje układu włókien w przekroju poprzecznym pręta, tj. włókna węglowe zlokalizowane w rdzeniu i w powierzchniowej warstwie pręta. 
a)

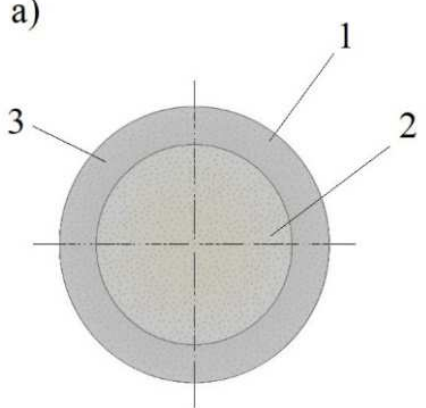

b)

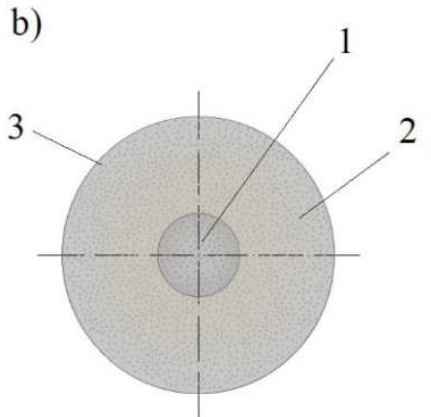

Rys. 1. Zaproponowane modele układu włókien w pręcie na bazie HFRP (a) położenie włókien węglowych na powierzchni (b) położenie włókien węglowych w rdzeniu (1) włókna węglowe (2) włókna bazaltowe (3) żywica epoksydowa

Fig. 1. Proposed model of the bar made on the basis of HFRP (a) location of carbon fibres in the region near the edge (b) location of carbon fibres in core region (1) carbon fibres (2) basalt fibres (3) epoxy resin

\section{Mechanika pręta}

\subsection{Właściwości mechaniczne składników pręta}

Nośność pręta zależy od właściwości mechanicznych tworzących go składników (Tabela 1).

Matryca wykazuje się brakiem zróżnicowania właściwości fizycznych niezależnie od rozpatrywanego kierunku. Włókna wzmacniające FRP wykazują w różnym stopniu własności anizotropowe. Włókna bazaltowe BFRP podobnie jak szklane GFRP charakteryzują się stosunkiem modułów sprężystości zbliżony do jedności. Włókna węglowe są silnie anizotropowe, stosunek modułów jest dużo wyższy.

Tabela 1. Parametry składników użytych w niniejszej pracy, na podstawie [3, 4, 8]

Table 1. Parameters of constituents utilized in this work, based on $[3,4,8]$

\begin{tabular}{|c|c|c|c|c|}
\hline Składniki / parametry & $\begin{array}{c}\text { Żywica } \\
\text { epoksydowa }\end{array}$ & $\begin{array}{c}\text { Włókna } \\
\text { węglowe }^{\text {a }}\end{array}$ & $\begin{array}{c}\text { Włókna } \\
\text { bazaltowe }\end{array}$ & $\begin{array}{c}\text { Włókna } \\
\text { szklane b }\end{array}$ \\
\hline Kierunkowość właściwości & izotropia & anizotropia & anizotropia & anizotropia \\
\hline Gęstość, $\mathrm{g} / \mathrm{cm}^{3}$ & 1.16 & $1.90-2.10$ & $2.60-2.80$ & $2.40-2.50$ \\
\hline Średnica, $\mu \mathrm{m}$ & - & $7.00-11.00$ & $11.2-13.4$ & $6.00-21.00$ \\
\hline $\mathrm{E} 11, \mathrm{GPa}$ & 3.45 & 232.00 & 89.00 & 73.10 \\
\hline $\mathrm{E} 22, \mathrm{GPa}$ & 3.45 & 15.00 & 89.00 & 73.10 \\
\hline$v 12$ & 0.35 & 0.279 & 0.26 & 0.22 \\
\hline$v 23$ & 0.35 & 0.49 & 0.26 & 0.22 \\
\hline $\mathrm{G} 12, \mathrm{MPa}$ & 1.28 & 24.00 & 21.70 & 29.95 \\
\hline $\mathrm{G} 23, \mathrm{MPa}$ & 1.28 & 5.03 & 21.70 & 29.95 \\
\hline $\begin{array}{c}\text { Wytrzymałość na roz- } \\
\text { ciąganie, } \mathrm{MPa}\end{array}$ & $55-130$ & $2500-3500$ & $1153-2100$ & $600-1437$ \\
\hline
\end{tabular}

$\mathrm{a}$ - Low Strength carbon fibres (LS carbon fibres); b - E-Glass fibres 


\subsection{Właściwości mechaniczne pręta}

Sposób ułożenia włókien w przekroju poprzecznym w rzeczywistości nie jest $\mathrm{w}$ pełni równomierny. $\mathrm{W}$ obliczeniach przyjmuje się uproszczone modele rozmieszczenia włókien: kwadratowe, prostokątne i heksagonalne. Wybór modelu determinuje ilość zmiennych materiałowych. Układ heksagonalny odpowiada izotropii transwersalnej - właściwości materiału są jednakowe jedynie w płaszczyźnie prostopadłej do kierunku włókien (Rys. 2).

a)

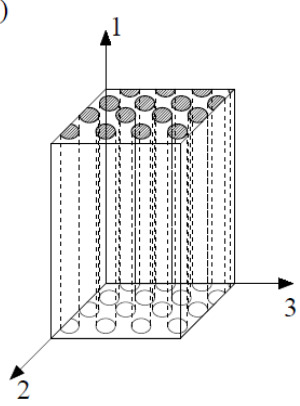

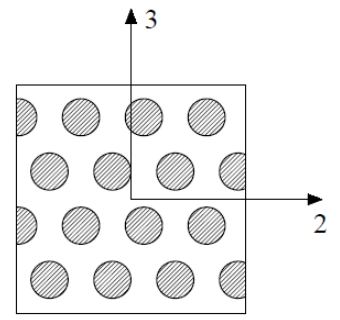

Rys. 2. Heksagonalna konfiguracja włókien (a) widok z boku (b) widok z góry

Fig. 2. Hexagonal configuration: a) side view, b) top view

Moduł sprężystości wzdłuż włókien jest jedną z najważniejszych właściwości mechanicznych, ponieważ jest on głównym czynnikiem wpływającym na sztywność konstrukcji.

W literaturze wykazano, że właściwości w kierunku podłużnym pręta mogą być przewidywane według prawa mieszanin $[9,6,1]$. Moduł sprężystości w kierunku podłużnym można uzyskać ze wzoru:

$$
E_{11}=E_{m} V_{m}+\sum_{i} E_{11, f i} V_{f i}
$$

gdzie: $E_{11, f i}$ i $E_{m}$ - moduły sprężystości, odpowiednio włókien i matrycy,

$V_{f i}$ i $V_{m}$ - udziały objętościowe, odpowiednio włókien i matrycy.

W podobny sposób można przeprowadzić obliczenia dla wytrzymałości na rozciąganie $\mathrm{i}$ innych mechanicznych właściwości w kierunku podłużnym.

Zależność pomiędzy stosunkiem objętości włókien a modułem sprężystości oraz wytrzymałością na rozciąganie w kierunku podłużnym, pokazana jest dla różnych rodzajów prętów na Rys. 3. 

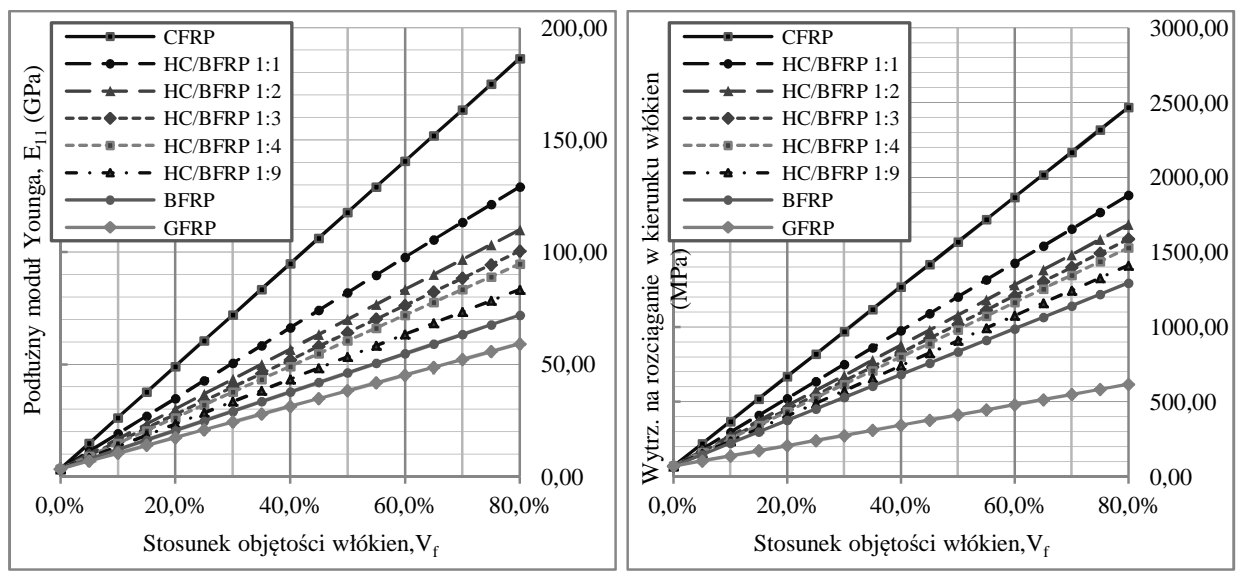

Rys. 3. Zależność pomiędzy stosunkiem objętości włókien i (a) modułem sprężystości w kierunku podłużnym (b) wytrzymałością na rozciąganie w kierunku podłużnym

Fig. 3. Dependence between volume fraction of fibres and (a) modulus of elasticity in longitudinal direction (b) tensile stress in longitudinal direction

\section{Analiza wpływu układu włókien na właściwości mechaniczne}

Analizę wpływu układu włókien dokonano poprzez modelowanie rozciągania prętów HFRP w programie ANSYS. Symulację przeprowadzono dla prętów o przekrojach zaprezentowanych $\mathrm{w}$ Tabeli 2 . Do porównania mechanicznych właściwości różnych układów włókien w pręcie HFRP wykorzystano włókna węglowe o niskiej wytrzymałości (LS Carbon fibres) i wysokim module sprężystości (High Modulus Carbon Fibres).

Tabela 2. Rodzaje prętów HFRP wziętych pod uwagę w analizie

Table 2. Types of HFRP bars taken into account in the analysis

\begin{tabular}{|c|c|c|}
\hline \multirow{2}{*}{ Rodzaj pręta HFRP } & \multicolumn{2}{|c|}{ Położenie włókien węglowych } \\
\cline { 2 - 3 } & $\begin{array}{c}\text { Na po- } \\
\text { wierzchni }\end{array}$ & W rdzeniu \\
\hline Hybrid C/BFRP $(1: 1)$ & BC.1.a & BC.1.b \\
\hline Hybrid C/BFRP $(1: 2)$ & BC.2.a & BC.2.b \\
\hline Hybrid C/BFRP $(1: 3)$ & BC.3.a $.3 . a$ \\
\hline Hybrid C/BFRP $(1: 4)$ & BC.4.a & BC.4.b \\
\hline Hybrid C/BFRP $(1: 9)$ & BC.5.a & BC.5.b \\
\hline
\end{tabular}

Otrzymane wyniki (Tabela 3) posłużyły do obliczenia modułu sprężystości podłużnej prętów HFRP. Rezultaty zestawiono z wartościami uzyskanymi zgodnie z prawem mieszanin. 
Tabela 3. Wyniki obliczeń modułu sprężystości podłużnej prętów HFRP

Table 3. Results of calculations of longitudinal modulus of elasticity in HFRP bars

\begin{tabular}{|c|c|c|c|c|}
\hline \multirow{3}{*}{$\begin{array}{c}\text { Rodzaj pręta } \\
\text { HFRP }\end{array}$} & \multicolumn{4}{|c|}{ Moduł sprężystości podłużnej, $\mathrm{E}_{11}(\mathrm{GPa})$} \\
\hline & \multicolumn{2}{|c|}{ HC/BFRP (LS CFRP ) } & \multicolumn{2}{|c|}{ HC/BFRP (HM CFRP) } \\
\hline & $\mathrm{ROM}^{\mathrm{a}}$ & FEM $^{\mathrm{b}}$ & $\mathrm{ROM}^{\mathrm{a}}$ & FEM $^{\mathrm{b}}$ \\
\hline BC.1.a & \multirow{2}{*}{129.09} & 127.81 & \multirow{2}{*}{356.29} & 344.30 \\
\hline BC.1.b & & 129.20 & & 348.99 \\
\hline BC.2.a & \multirow{2}{*}{110.02} & 110.54 & \multirow{2}{*}{261.49} & 260.78 \\
\hline BC.2.b & & 109.10 & & 251.12 \\
\hline BC.3.a & \multirow{2}{*}{100.49} & 101.05 & \multirow{2}{*}{214.09} & 214.80 \\
\hline BC.3.b & & 100.01 & & 207.45 \\
\hline BC.4.a & \multirow{2}{*}{94.77} & 93.56 & \multirow{2}{*}{185.65} & 178.35 \\
\hline BC.4.b & & 93.55 & & 181.86 \\
\hline BC.5.a & \multirow{2}{*}{83.33} & 83.02 & \multirow{2}{*}{128.77} & 126.82 \\
\hline BC.5.b & & 82.92 & & 125.72 \\
\hline
\end{tabular}

a - wartości obliczone analitycznie według reguły mieszanin (ROM)

b - wyniki numeryczne uzyskane według metody elementów skończonych (FEM)

W przypadku wykorzystania w analizach włókien węglowych LS wyniki analityczne pokrywają się z numerycznymi - maksymalny błąd nie przekracza $1.3 \%$. Zastosowanie włókien węglowych HM powoduje zwiększenie rozbieżności w wynikach do prawie $4.0 \%$.

\section{Wnioski i podsumowanie}

Przeprowadzone obliczenia wykazały, że zastąpienie w pręcie HC/BFRP części włókien bazaltowych, włóknami węglowymi ma korzystny wpływ na jego właściwości mechaniczne. Już 10-procentowa substytucja włóknami węglowymi LS powoduje wzrost modułu sprężystości podłużnej o 16,0\% i wytrzymałości na rozciąganie o $9,0 \%$.

Obliczenia właściwości mechanicznych przeprowadzone według prawa mieszanin nie uwzględniają żadnego zróżnicowania, w zależności od lokalizacji w przekroju poprzecznym włókien o lepszej charakterystyce mechanicznej. Badania eksperymentalne prowadzone dla prętów HFRP zawierających włókna węglowe i szklane [2] wskazują, że konfiguracja włókien rzutuje na właściwości mechaniczne prętów. Lepsze parametry osiągnięto przy układzie z włóknami węglowymi w rdzeniu przekroju. Na podstawie rezultatów przeprowadzonego modelowania numerycznego nie można jednoznacznie wnioskować, która konfiguracja włókien węglowych jest korzystniejsza z punktu widzenia kształtowania właściwości mechanicznych prętów. Sugerowane jest zatem przeprowadzenie badań eksperymentalnych w tym zakresie. 


\section{Podziękowanie:}

Artykut powstat $w$ oparciu o projekt pt. „Innowacyjne hybrydowe zbrojenie kompozytowe FRP do konstrukcji infrastrukturalnych o podwyższonej trwatości” realizowanego w ramach Programu Badań Stosowanych NCBR: PBS3/A2/20/2015.

\section{Literatura}

[1] Abdel Gfahaar M., Mazen A.A., El-Mahallawy N.A.: Application of the rule of mixtures and Halpin-Tsai equations to woven fabric reinforced epoxy composites, Journal of Engineering Sciences, vol. 34, 2006, pp. 227-236.

[2] Bakis C. E., Nanni A., Terosky J. A., Koehler S. W.: Self-Monitoring, PseudoDuctile, Hybrid FRP Reinforcement Rods for Concrete Applications, Composites Science and Technology, 2001, pp.815-823.

[3] Chikhradze N.M., Japaridze L.A., Abashidze G.S.: Properties of Basalt Plastics and of Composites Reinforced by Hybrid Fibers in Operating Conditions, Composites and Their Applications, 2012, pp. 221-246, http://www.intechopen.com.

[4] Dorigato A., Pegoretti A.: Flexural and impact behaviour of carbon/basalt fibers hybrid laminates, Journal of Composite Materials, vol. 48, 2014, pp. 1121-1130.

[5] Garbacz A., Urbański M., Łapko A.: BFRP bars as an alternative reinforcement of concrete structures - Compatibility and adhesion issues, Advanced Material Research, Vol 1129, 2015, pp.233-241.

[6] Kormanikova E., Kotrasova K.: Elastic mechanical properties of fiber reinforced composite materials, Chem. Listy 105, LMV 2010 Regular Papers, 2011, pp. 758-762.

[7] Mufti A., Erki MA., Jaeger L.: Advanced composites materials with application to bridges, Canadian Society of Civil Engineers, 1991, Montreal, Canada.

[8] Parnas R., Shaw M., Liu Q.: Basalt Fiber Reinforced Polymer Composites, Technical Report, Storrs, the USA, 2007.

[9] Piekarski R.: Porównanie wybranych teorii sztywności kompozytów FRP, Wydawnictwo Politechniki Częstochowskiej, Kompozyty, r. 6, nr 1, s. 26-31.

[10] Urbański M., Łapko A.: Przyczynek do oceny stanu zarysowania belek z betonu zbrojonego prętami BFRP, Budownictwo i Architektura 13(3), 2014, s. 201-208.

[11] Wang X., Wu G., and Wu Z.: Tensile property of prestressing basalt FRP and hybrid FRP tendons under salt solution, Proc., 6th Int. Conf. on FRP Composites in Civil Engineering, 2012, pp. 1-8.

[12] Wu Z., Wang X., Wu G.: Basalt FRP composite as a reinforcement in infrastructure (keynote paper), the seventeenth annual international conference on composites/nano engineering (ICCE-17), 2009, Hawaii, USA.

\section{INFLUENCE OF SUBSTITUTION OF BASALT FIBRES BY CARBON FIBRES ON THE MECHANICAL PROPERTIES OF B/CFRP (HFRP)}

\section{S u m m a r y}

This paper introduces both an analytical and numerical study that investigates the mechanical performance of recently developing HFRP bars, which were created by substitution of the part of basalt fibres BFRP by the part of carbon fibres CFRP. In this aspect the term "substitution" 
might be understood as modification of BFRP bars, where part of basalt fibres will be replaced by carbon fibres. Substitution is aimed at achieving of better properties in obtained material.

The objective of this study is to identify optimal model of HFRP bars, which provides an alternative to steel bars for enhancing concrete structures. Replacing of basalt fibres by carbon fibres provides better properties in mechanical performance of the bars. From economical point of view, for HFRP bars in combination with basalt fibres it is proposed to use carbon fibres with low strength (LS carbon fibres) and relatively small amount of volume fraction of carbon fibres to whole amount of fibres.

This work represents description of the hybrid bar structure, estimation of properties of the bar in fibre and transverse directions and influence of fibre arrangement on mechanical properties of the bar. Analysis was performed for bars with different ratio between fibres of carbon and fibres of basalt $(1: 9 ; 1: 4 ; 1: 3 ; 1: 2 ; 1: 1)$.

Investigations were done for two different bar architecture arrangements, where carbon fibres are estimated in the first case in the region near the edge and in another case in core region.

Keywords: Hybrid C/BFRP bar, HFRP, BFRP, CFRP, bar architecture

Przestano do redakcji: 07.06.2016 r.

Przyjęto do druku: 30.06.2016 r.

DOI: $10.7862 / \mathrm{rb} .2016 .17$ 